\title{
A TRADUÇÃO COMO UM ‘ACORDO DIALÓGICO’: UMA PERSPECTIVA BAKHTINIANA ${ }^{1}$
}

\author{
Amith P. V. Kumar ${ }^{1}$ \\ 1 The English and Foreign Languages University \\ Hyderabad, Telangana, India
}

Tradução de: Orison Marden Bandeira de Melo Jr. ${ }^{2}$

${ }_{2}^{2}$ Universidade Federal do Rio Grande do Norte

Natal, Rio Grande do Norte, Brasil

\begin{abstract}
Resumo: A teoria dialógica de Mikhail Bakhtin (1895-1975) oferece um potencial aberto para uma tradutibilidade criativa de culturas. Ao capacitar o tradutor a incorporar os traços culturais da cultura-fonte e da cultura-alvo, o dialogismo provê uma saída ao dilema entre lealdade e liberdade que incomoda os estudos da tradução há anos. Uma teoria bakhtiniana da tradução entrelaça os "fios dialógicos vivos" entre cultura-fonte e cultura-alvo, a fim de criar um ambiente de abertura. Este artigo explora os vários significados do termo "diálogo" e busca mostrar a significação e as implicações da compreensão da tradução como uma interanimação no sentido bakhtiniano.
\end{abstract}

Palavras-chave: tradução; Mikhail Bakhtin; Acordo dialógico; Alteridade; Monologismo; Enunciados; Inacabamento.

\footnotetext{
${ }^{1}$ Esta é uma tradução do artigo Translation as 'Dialogic Agreement': A Bakhtin's Perspective, publicado no International Journal of English and Literature (IJEL), v. 4, n. 6, 2014. A publicação da tradução foi autorizada pelo autor, Dr. Amith P. V. Kumar, em e-mail enviado no dia 22 de junho de 2017, e do editor chefe do periódico, em e-mail enviado no dia 21 de agosto de 2017. O texto em inglês está disponível em: < http://www.tjprc.org/publishpapers/--1467378588-13.EnglishIJEL-Translation as Dialogic Agreement-AMITH KUMAR P V.pdf > .
} 


\title{
TRANSLATION AS 'DIALOGIC AGREEMENT': A BAKHTIN'S PERSPECTIVE
}

\begin{abstract}
Mikhail Bakhtin's (1895-1975) theory of dialogism offers an open-ended potential for a creative translatability of cultures. By enabling a translator to incorporate the cultural traces of both the source culture and the target culture, dialogism provides an outlet to the dilemma between loyalty and freedom that has bothered translation studies for years. A Bakhtinian theory for translation interweaves "living dialogic threads" between the source-culture and the target-culture to create an ambience of open-endedness. This paper explores the various meanings of the term "dialogue" and attempts to show the significance and implications of understanding the activity of translation as dialogic interanimation in the Bakhtinian sense.

Keywords: Translation; Mikhail Bakhtin; Dialogic agreement; Otherness; Monologism; Utterances; Unfinalizability.
\end{abstract}

\section{Introdução}

As teorias contemporâneas da tradução oferecem perspectivas múltiplas para a compreensão da complexidade do processo tradutório. Enquanto as teorias tradicionais estavam preocupadas com um significado determinável no texto original e sua substituição com significados secundários no texto traduzido, as teorias pós -estruturalistas, em especial a desconstrução, questionam a noção de "original". Por outro lado, os hermenêuticos sugerem que a tradução deve, segundo Gutt (2000, p. 377), "lembrar, interpretativamente, o original" de tal forma que produza "efeitos contextuais apropriados"2. Os teóricos pós-coloniais da tradução ampliaram a hipótese de Foucault com vistas a defender a tradução como sendo pautada pela operação de relações de poder. Os teóricos dos estudos culturais compreendem a tradução como uma atividade que

2 No original: "interpretively resemble the original"; "adequate contextual effects". 
ilustra a "marca da diferença" entre várias comunidades onde "a relação do um com o outro" é de significado fundamental (KEITH, 2000, p. 466) $)^{3}$.

Entretanto, uma abordagem que tem como base a teoria de Mikhail Bakhtin ainda não recebeu a devida atenção. Por meio dela, a tradução é analisada como "diálogo" em que ambos o texto-fonte e o texto-alvo se constituem devido às relações que eles mesmos criam para si.

O dialogismo bakhtiniano é um fenômeno complexo que desafia a definição. Diferentemente do estruturalismo e do formalismo, que são filosofias mais coesas e sistemáticas, o pensamento de Bakhtin é marcado por quebras, lacunas e descontinuidades. A vida atribulada do autor e sua carreira conturbada na Rússia stalinista também ecoam nos seus conceitos e princípios que possuem tons de obscuridade e elementos de difícil compreensão. No entanto, certamente podemos encontrar um interesse indubitável de Bakhtin pelo termo "diálogo". Apesar de, no sentido lato, ele ser usado para denotar comunicação entre dois ou mais indivíduos, o diálogo em Bakhtin se refere tanto à ação quanto à cognição humana. Um dos significados do termo está relacionado ao diálogo que ocorre quanto duas vozes reivindicam sua presença por meio de uma concordância ou discordância mútua. Para Bakhtin, uma voz única ou uma existência singular não consegue produzir quaisquer significados, tendo em vista a sua existência não encontrar uma resposta. "Todo discurso está voltado para uma resposta e não pode evitar a influência profunda do discurso responsivo antecipável" (BAKHTIN, 2015, p. 52, grifos do autor $)^{4}$.

Bakhtin também utiliza o termo diálogo para se referir às concordâncias e discordâncias constantes que acontecem no interior da língua. Nas suas próprias palavras, "[a] linguagem só vive na comunicação dialógica daqueles que a usam” (BAKHTIN, 2010,

\footnotetext{
${ }^{3}$ No original: "trace of difference"; "the relation of the one to the other".

${ }^{4}$ BAKHTIN, M. Teoria do romance I: a estilística. Trad. Paulo Bezerra. São Paulo: Editora 34, 2015.
} 
p. 209) ${ }^{5}$. Como os padrões de uso da linguagem entre comunidades de fala nunca são os mesmos, Bakhtin identifica linguagens individuais como enunciados. Para ele, há uma articulação dialógica e uma aceitação dialógica de enunciados que constituem a existência humana. Para Bakhtin, "[c]ada enunciado é um elo na corrente complexamente organizada de outros enunciados" (2016, p. 26); "todo enunciado é um elo na cadeia da comunicação discursiva" (2016, p. 46-47) ${ }^{6}$. O significado é constituído, apropriado e reconhecido dialogicamente em relação aos discursos que emergem das tradições e interesses culturais.

Entretanto, em um nível profundo, o eu e o outro definem a sua relação por meio da linguagem. Nesse sentido, o termo adquire um significado ontológico, já que a existência humana é sempre dialógica. Em outras palavras, o eu é reconhecido somente se ele for definido, reconhecido e re-conhecido pelo outro. A consciência é sempre uma consciência para o outro, tendo em vista que uma consciência única é insignificante, comparada à não existência e à morte. Segundo Michael Holquist, "[n]o dialogismo, a própria capacidade de ter uma consciência tem como base a alteridade [...] no dialogismo, a consciência é alteridade" (1990: 18; grifos do articulista $)^{7}$. O monologismo, por outro lado, é caracterizado por uma noção singular e unitária que leva a uma percepção limitada da verdade. Contra essa verdade monológica, Bakhtin enfatiza uma concepção não sistêmica da verdade, ou seja, uma concepção não monológica e pluralística. O entendimento hegeliano da oposição dialética que resultaria na compreensão do espírito absoluto é inaceitável a Bakhtin. Esse entendimento não apenas torna monológica a investigação filosófica, mas também leva ao "teoricismo abstrato". Contrário à evolução dialética do espírito, Bakhtin está

${ }^{5}$ BAKHTIN, M. Problemas da poética de Dostoiévski. Trad. Paulo Bezerra. 5. ed. Rio de Janeiro: Forense Universitária, 2010.

${ }^{6}$ BAKHTIN, M. Os gêneros do discurso. In: Os gêneros do discurso.

Trad. Paulo Bezerra. São Paulo: Editora 34, 2016. p. 11-69.

${ }^{7}$ No original: "[i]n dialogism the very capacity to have consciousness is based on otherness $[\ldots]$ in dialogism consciousness is otherness". 
interessado na interanimação dialógica da "realidade multinivelada”. Somente um diálogo genuíno nos ajudaria a conceber uma verdade não monológica.

Após a investigação dos vários significados do termo diálogo, mudemos o foco para o processo de tradução. Certamente, tradução não é uma atividade que surge em um vácuo, ausente de qualquer tipo de referência a outra língua ou cultura. É sempre a respeito de duas entidades situadas em diferentes categorias de tempo e espaço. A tradução surge como um resultado de uma interação entre duas línguas/culturas que se representam em dois textos que chamamos de texto-fonte e texto-alvo. J. Levy (apud BASSNETT, 2002, p. 16) ressalta que

[u]ma tradução não é uma composição monística, mas uma interprenetração e um conglomerado de duas estruturas. Por um lado, há o conteúdo semântico e o contorno formal do original; por outro, há o sistema inteiro de características estéticas vinculado à língua da tradução. ${ }^{8}$

Essa natureza não monística da tradução nos capacita a entender a atividade da tradução como um diálogo bakhtiniano. A tradução, ao expandir a sua influência do texto-fonte a outra cultura, contribui para a natureza aberta do texto e preserva vivo o diálogo iniciado pelo texto-fonte entre seus leitores. Nesse sentido, é a "palavra responsiva" ao texto-fonte. Ademais, uma tradução é direcionada aos leitores da cultura-alvo, por isso a tarefa do tradutor também é compor uma "palavra responsiva" que possa atendar às expectativas dos leitores-alvo, sendo-lhe confiada a tarefa complexa de falar tanto para a cultura-fonte quanto para a

\footnotetext{
${ }^{8}$ No original: “A translation is not a monistic composition, but an interpenetration and conglomerate of two structures. On the one hand there are the semantic content and the formal contour of the original, on the other hand, the entire system of aesthetic features bound up with the language of the translation".
} 
cultura-alvo. Qualquer prioridade dada a uma das culturas pode ser danosa à atividade em questão.

A tradução também é um diálogo de acordo com o segundo sentido do termo, pois é o produto de uma "interação dialógica" entre línguas e culturas, que requer um entendimento meticuloso do dialogismo interno do texto-fonte e do texto-alvo. Para o tradutor, o que se torna importante é a tradução da dialogicidade interna da língua/cultura do texto fonte para um auditório-alvo. Esse processo tradutório demanda uma investigação apurada da dinâmica interna da cultura-fonte e da cultura-alvo. O tradutor tem de criar um acordo dialógico no enunciado novo que está produzindo para um novo grupo de leitores. Semelhantemente ao diálogo, que se direciona ao outro em busca de uma "resposta", a tradução é sempre orientada para o outro, ou seja, para o auditório da cultura de recepção, alterando-se e modificando-se ao se mover nas conexões intersubjetivas que cria para si. No sentido bakhtiniano, o espaço dialógico da tradução é um "ambiente cheio de tensão", caracterizado por concordâncias e discordâncias.

Em um plano filosófico, a tradução é sempre sobre o "eu" e o outro, e o diálogo no terceiro sentido não prioriza o primeiro em relação ao segundo, mas constrói uma ponte entre os dois para que haja interação e entendimento mútuos. Para Bakhtin, o evento da vida encontra significado quando há um "co-ser”, ou seja, quando ambos co-existem. Nas palavras de Holquist,

\begin{abstract}
“Tanto/quanto" não é uma mera oscilação entre duas possibilidades mutualmente exclusivas, sendo cada uma, por si só, lógica e consistente, garantindo, dessa forma, a possibilidade ulterior da verdade, tendo em vista que uma lógica desse tipo restritivo é tão limitadora que apenas uma das opções pode estar correta. O diálogo tem sua própria lógica, mas não desse tipo exclusivo (1990, p. 41)9.
\end{abstract}

\footnotetext{
${ }^{9}$ No original: “'Both/and' is not a mere wavering between two mutually exclusive possibilities, each of which is in itself logical and consistent, thus insuring the further possibility of truth, since a logic of this restrictive sort is so limiting that
} 
A tradução requer o mesmo "dialogismo" entre o eu e outro. Esse "dialogismo" exige uma apreciação da cultura da língua-fonte e da cultura de língua-alvo. Para um tradutor, a consciência, no sentido bakhtiniano, é sempre a consciência sobre o outro. $\mathrm{O}$ outro aqui não é simplesmente a cultura da língua-fonte, mas é também a cultura da língua-alvo. Há uma antecipação de ambos os lados e, diante disso, uma tradução deve abordar os dois. É por essa razão que não seria inapropriado concluir que a tradução é o produto de um evento dialógico, isto é, um empreendimento aberto que envolve um entendimento criativo do eu e do outro.

A noção bakhtiniana de "extralocalidade" tem implicações fundamentais para um tradutor. Para Bakhtin, a compreensão depende da habilidade de o sujeito situar o eu na posição do outro para que possa retornar à sua posição e finalizar a tarefa criativa. Segundo Bakhtin, "[a] grande causa para a interpretação é a distância do intérprete - no tempo, no espaço, na cultura - em relação àquilo que ele pretende interpretar de forma criadora" (2017, p. 18, grifo do autor $)^{10}$. Bakhtin chama essa compreensão de "ativa", contrapondo-a à "compreensão passiva", em que o eu dissolve a sua individualidade por inteiro ao imergir no território do outro. A “compreensão passiva” é monológica, porque permite a existência de apenas uma perspectiva. Diante disso, a realização de uma tarefa criativa é impossível por meio de uma "compreensão passiva", tendo em vista que ela impede a diferença entre o eu e o outro.

A tradução é, antes de tudo, a compreensão das sutilezas intra e interlinguais. George Steiner (1977) afirma que "quando duas ou mais línguas estão em uma interconexão articulada, as barreiras no meio delas estão obviamente mais salientes e o empreendimento

only one of the two options can be correct. Dialogue has its own logic but not of this exclusive kind".

${ }^{10}$ BAKHTIN, M. A ciência da literatura hoje (resposta a uma pergunta da revista Novi Mir). In: . Notas sobre literatura, cultura e ciências humanas. Trad. Paulo Bezerra. São Paulo: Editora 34, 2017. p. 9-19. 
pela inteligibilidade, mais consciente" (p. 47) ${ }^{11}$. Este "empreendimento pela inteligibilidade" requer, bakhtinianamente falando, uma "compreensão ativa". Não se exige do tradutor uma empatia com o texto fonte ou com os leitores-alvo, resultando na sua perda de identidade. Recentemente é isso o que acontece com as teorias tradicionais de tradução e as teorias voltadas à recepção. Ao considerar a tradução como uma atividade secundária ou ao procurar destruir a noção de texto-fonte, as teorias da tradução advogam por uma "compreensão passiva". O que é exigido, pelo contrário, é uma "entrada viva" 12 no território do outro. Segundo Bakhtin, "[e]u vivo ativamente a empatia com uma individualidade, e, por conseguinte, nem por um instante sequer perco completamente a mim mesmo, nem perco o meu lugar único fora dela" (BAKHTIN, 2010, p. 62) ${ }^{13}$.

Esse ato dialógico capacita o tradutor a reter a diferença entre o eu e o outro. Dessa forma, a tradução terá uma voz própria que não

11 Texto no original: "Where two or more languages are in articulate interconnection, the barriers in the middle will obviously be more salient, and the enterprise of intelligibility more conscious".

${ }^{12}$ N. do T.: Essa "entrada viva" refere-se à interpretação dada por Morson e Emerson, em sua introdução ao livro Rethinking Bakhtin: Extensions and Challenges, ao vocábulo vzhivanie. Para os autores, vzhivanie não deve ser entendido como empatia, porque o termo pressuporia a imersão total de um no sofrimento do outro, experimentando o mundo do outro pela perspectiva do outro. Para eles, vzhivanie refere-se à entrada no mundo do outro, permanecendo no seu próprio lugar, na sua própria exotopia em relação ao lugar do outro (MORSON; EMERSON, 1989, p. 1-60). Entretanto, é importante a menção de que, na tradução de Vadim Liapunov ao inglês de Para uma filosofia do ato responsável (BAKHTIN, M. Toward a Philosophy of the Act. Translation and notes by Vadim Liapunov. Austin: University of Texas Press, 1993) e na de Tatiana Bubnova (BAJTIN, M. Hacia una filosofía del acto ético. Traducción de Tatiana Bubnova. In:

Hacia una filosofía del acto ético. De los borradores y otros escritos. Rubí (Barcelona): Anthropos; San Juan: Universidad de Puerto Rico, 1997. p. 7-81), encontramos ter empatialempatia (empathizelempatía), como é visto na citação logo a seguir no texto.

${ }^{13}$ BAKHTIN, M. Para uma filosofia do ato responsável. Organizado por Augusto Ponzio e GEGE/UFSCar. Tradução de Valdemir Miotelo e Carlos Alberto Faraco. São Carlos: Pedro \& João Editores, 2010. 
será categorizada nem como uma imitação do original, nem como um trabalho completamente desconexo. É a "compreensão ativa" que torna a tradução uma "palavra responsiva".

A priorização, qualquer que seja, elimina a possibilidade de haver uma "compreensão ativa" para a execução da atividade tradutória. Uma abordagem monológica erra ao não reconhecer os diálogos intra- e inter-textos durante a tradução. Uma abordagem dialógica pede uma compreensão dos "graus de alteridade" entre a cultura-fonte e a cultura-alvo e um entendimento da relação dinâmica entre o eu e o outro, que está sempre no processo de "ser feita e desfeita" (HOLQUIST, 1990, p. 29) ${ }^{14}$. Dessa forma, essa compreensão transcende a pretensão de subjetividade e objetividade, pois visa a criar uma condição de compreensão compartilhada e de coexistência exigida na tarefa de tradução.

Ao termos estabelecido a relevância dos princípios dialógicos para a tradução, devemos explorar, agora, o que Bakhtin chama de "metalinguística" e o seu papel crucial para um tradutor. Em $\mathrm{O}$ texto na linguística, na filologia e em outras ciências humanas, Bakhtin identifica dois importantes "polos" num texto (2016, p. $74)^{15}$. O primeiro consiste no sistema da linguagem, ou seja, no sistema de signos que é repetível e reproduzível. No que tange aos elementos linguísticos e filológicos, um texto é inconcebível sem este polo: qualquer texto pressupõe um sistema de linguagem e passa a existir devido a esse sistema.

Entretanto, todo texto é único por direito. De forma bastante convincente, Bakhtin defende a existência de características extralinguísticas no texto que são irrepetíveis e irreproduzíveis. Este é o segundo polo, ou seja, o polo dialógico. As características extralinguísticas referem-se ao plano e propósito do autor, a qualidades como a honestidade, verdade e beleza do texto, aos significados

14 Texto no original: "being made and unmade".

${ }^{15}$ BAKHTIN, M. O texto na linguística, na filologia e em outras ciências humanas. In: . Os gêneros do discurso. Tradução de Paulo Bezerra. São Paulo: Editora 34, 2016. p. 71-107. 
contextuais e sua implicação para o emissor e receptor, às dimensões temporais e espaciais do texto etc. O sentido não depende muito do sistema da linguagem; ele é, pelo contrário, um produto do sistema dialógico do texto, o seu segundo polo. O estudo dessas características que vão para além dos limites da linguística adquire uma importância fundamental para Bakhtin. Ela chama esse estudo de Metalinguística (BAKHTIN, 2010, p. 207) ${ }^{16}$.

A metalinguística foi chamada de "translinguística" por teóricos como Julia Kristeva (KRISTEVA, 1980, p. 66). O foco aqui, entretanto, são as dimensões sociológicas da linguagem e não as suas características formais e codificadas. Sob a influência de linguistas como Ferdinand de Saussure e de formalistas como Roman Jakobson, o estudo de língua e de literatura tornou-se um estudo de normas e desvios. Para Bakhtin, um estudo de características fixas e convencionais não é apenas uma investigação acabada, que exige nosso comprometimento com o "teoricismo", mas também uma descontextualização da linguagem e da vida. Segundo ele, “[o] código é apenas um meio técnico de informação, não tem importância cognitiva criadora. O código é um contexto deliberadamente estabelecido, amortecido" (BAKHTIN, 2017, p. 44) ${ }^{17}$.

Bakhtin entende que a linguagem compreende vários gêneros do discurso, desde os discursos do cotidiano até os discursos literários. Esses gêneros discursivos diferem-se em relação às suas vozes, entonações e aos momentos singulares nos quais os enunciamos. Dessa forma, para Bakhtin, a unidade básica do discurso é o enunciado. Diferentemente de uma oração que pode ser repetida qualquer número de vezes, um enunciado não pode ser repetido completamente, quer seja na mesma língua ou não. É, portanto, extralinguístico, haja vista que está direcionado ao outro para responder a ele. Para Morson e Emerson (2001, p.

${ }^{16}$ Para a referência da obra, cf. nota de rodapé 5.

${ }^{17}$ BAKHTIN, M. Fragmentos dos anos 1970-1971. In: Notas sobre literatura, cultura e ciências humanas. Trad. Paulo Bezerra. São Paulo: Editora 34, 2017. p. 21-56. 
125), "enunciados podem ser pequenos como um grunhido ou longos como Guerra e Paz"18.

Voltemos a nossa atenção à tradução. O tradutor é, em primeiro lugar, um leitor. O texto-fonte é o enunciado do autor/emissor direcionado ao leitor/receptor. Como esse enunciado é irrepetível, um tradutor não pode imitá-lo ou refleti-lo como espelho. É necessário, no entanto, ter cuidado com a conclusão de que, para Bakhtin, como os enunciados são irreproduzíveis, eles não podem ser traduzidos. Uma negação da tradução significaria uma existência monológica, semelhante a uma não existência. A filosofia bakhtiniana, de certa forma, precisa da tradução, tendo em vista que é somente por meio da tradução que um texto-fonte conserva o seu espírito dialógico noutra cultura.

Há uma questão crucial a que um tradutor tem de responder: enquanto o sistema da linguagem de um texto é completamente traduzível em outro sistema de linguagem, como deve ser traduzido o sistema dialógico da língua, com os seus elementos inacabados? Como observamos anteriormente, o segundo polo é a singularidade do texto. Esse polo, que não apoia nem uma coerência lógica nem a um padrão linguístico, torna-se a questão principal para o tradutor. É possível, ao tradutor, realizar a tarefa de re-inventar o sistema dialógico para os seus leitores-alvo, situados em um tempo, um espaço e uma cultura diferentes?

Responder a essa questão complexa exige uma compreensão das relações entre texto e contexto e entre autor e receptor. A "cadeia de significados" evocados pelo texto-fonte, entendido como enunciado, é o resultado da interação entre autor e leitor. Segundo Bakhtin, "[o] acontecimento da vida do texto, isto é a sua verdadeira essência, sempre se desenvolve na fronteira de duas consciências, de dois sujeitos" (2016, p. 76; grifos do autor) ${ }^{19}$. Isso não significa que devemos ignorar a relação entre texto e contexto

${ }^{18}$ Texto no original: "Utterances may be as short as a grunt and as long as War and Peace".

${ }^{19}$ Para a referência da obra, cf. nota de rodapé 15. 
- o contexto da escrita e o contexto da leitura são completamente diferentes. Os sentidos são produzidos a partir de uma rede compartilhada de relações entre texto e contexto e entre sujeito e leitor. No ensaio Bakhtin e o leitor, David Shepherd escreve que

\begin{abstract}
[...] é importante nunca perder de vista que a natureza do encontro entre texto e leitor é dialógica: se os sentidos do texto são indissociáveis da compreensão ativa do leitor, então o entendimento, por sua vez, dever ser, a rigor, igualmente indissociável do encontro com o texto, deve ser precisamente específico ao contexto $\left(1989\right.$, p. 99) ${ }^{20}$.
\end{abstract}

A análise de Shepard traz luz sobre o importante papel do contexto da leitura na compreensão ativa de um texto. Um novo contexto de leitura implica uma nova compreensão do texto, que implica, ainda, que todo ato de leitura é um decifrar de uma metalinguística diferente do texto. Para um tradutor, que lê o texto-fonte em um contexto específico, a compreensão do sistema dialógico do texto depende do momento singular da compreensão do texto. Podemos, dessa forma, avançar a ideia e defender que o contexto de leitura para um tradutor também é o momento quando ele compõe um novo sistema dialógico para os seus leitores-alvo. Assim, o encontro dialógico com o texto capacita o tradutor a implantar um novo segundo polo no seu enunciado.

\footnotetext{
${ }^{20}$ Texto no original: “[...] it is important never to lose sight of the fact that the character of the text-reader encounter is dialogic: if the meanings of the text are indissociable from the reader's active understanding, then that understanding in its turn must strictly speaking be equally undissociable from the encounter with the text, must be precisely context-specific".
} 


\section{Referências}

BAKHTIN, M. Problems of Dostoevsky's poetics. Editado e traduzido por Caryl Emerson. Minneapolis, MN: University of Minnesota Press, 1984. (Theory and History of Literature, n. 8).

. Discourse in the novel. In: . The dialogic imagination: four essays by M. M. Bakhtin. Traduzido por Caryl Emerson e Michael Holquist. Austin, TX: University of Texas Press, 1981. p. 259-422. (Slavic Series).

. Speech genres and other late essays. Editado por Caryl Emerson e Michael Holquist e traduzido por Vern W. McGee. Austin, TX: University of Texas Press, 1986.

BASSNETT, S. Translation studies. 3. ed. London; New York: Routledge, 2002.

GUTT, E-A. Translation as interlingual interpretive use. In: VENUTI, L. (Ed). The translation studies reader. London; New York: Routledge, 2000. p. 376-396.

HOLQUIST, M. Dialogism: Bakhtin and his world. London; New York: Routledge, 1990.

KEITH, H. Translating camp talk: gay identities and cultural transfer. In: VENUTI, L. (Ed). The translation studies reader. London; New York: Routledge, 2000. p. 446-467.

KRISTEVA, J. Desire in language: a semiotic approach to literature and art. Editado por Leon S. Roudiez e traduzido por Thomas Gora, Alice Jardine e Leon S. Roudiez. Oxford: Basil Blackwell, 1980.

MORSON, G.; EMERSON, C. (Ed.). Rethinking Bakhtin: extensions and challenges. Evanston, IL: North Western University Press, 1989.

. Mikhail Bakhtin: creation of a prosaics. Redwood City, CA: Stanford University Press, 2001. 
STEINER, G. After Babel: aspects of language and translation. Oxford: Oxford University Press, 1977.

SHEPHERD, D. Bakhtin and the reader. In: HIRSCHKOP, K.; SHEPHERD D. Bakhtin and cultural theory. Manchester; New York: Manchester University Press, 1989. p. 91-108.

Recebido em: 30/04/2018

Aceito em: 09/07/2018 Publicado em setembro de 2018

Orison Marden Bandeira de Melo Jr.E-mail: junori36@uol.com.br ORCID: https://orcid.org/0000-0002-7592-449X 